\title{
lodine-Catalyzed Prins Cyclization of Homoallylic alcohols
}

\author{
K. R. Kishore Kumar Reddy, Luiz F. Silva, Jr.*
}

Departamento de Química Fundamental, Instituto de Química - Universidade de São Paulo, Caixa Postal 26077, CEP 05513-970 São Paulo SP, Brazil.

\section{*luizfsjr@iq.usp.br}

Keywords: Prins cyclization, lodine, Hydropyrans.

\section{INTRODUCTION}

The Prins cyclization is one of the most effective methods for generating hydropyran derivatives and has been utilized in the synthesis of several biologically active natural products. ${ }^{1}$ Furthermore, there are few reports using ketones as the carbonyl component. ${ }^{2}$ By using one equivalent of $\mathrm{I}_{2}$, Yadav and co-workers developed a protocol for Prins cyclization. ${ }^{2}$ Recently our group discovered a new method using catalytic amount of $\mathrm{I}_{2}$ for Prins cyclization. ${ }^{3}$ Additional results are herein described.

\section{RESULTS AND DISCUSSION}

The reaction of $p$-anisaldehyde with various homoallylic alcohols gave the desired product, except for 5 (Table 1).

Table 1. Prins cyclization of alcohols and $p$-anisaldehyde.

\begin{tabular}{|c|c|}
\hline Entry & alcohol \\
\hline $4^{\mathrm{b}}$ & \\
\hline $5^{\mathrm{C}}$ & \\
\hline
\end{tabular}

${ }^{*}$ Conditions. a). $\mathrm{I}_{2}(5 \mathrm{~mol} \%), \mathrm{CH}_{2} \mathrm{Cl}_{2}$, reflux, 3h. b). $\mathrm{I}_{2}(10 \mathrm{~mol} \%), \mathrm{CH}_{2} \mathrm{Cl}_{2}$ reflux, 3h. c). $\mathrm{I}_{2}(2 \mathrm{~mol} \%), \mathrm{CH}_{2} \mathrm{Cl}_{2}$, reflux, 4 days. $\left(\mathrm{Ar}=p-\mathrm{OCH}_{3}-\mathrm{C}^{\wedge} \mathrm{H}_{4}-\right)$.

The Prins cyclization of homoallylic alcohols with several ketones was also investigated, showing the generality of the method (Table 2).

\section{CONCLUSION}

Several additional examples of the iodine-catalyzed Prins cyclization were performed, increasing the scope of this reaction. The behaviour of different homoallylic alcohols was investigated. Additionally, several ketones were used as the carbonyl component including aromatic ketones.
Table 2. Prins cyclization of alcohols and Ketones. ${ }^{a}$

(1)

\section{ACKNOWLEDGEMENTS}

CAPES, CNPq, and FAPESP for financial support.

\section{REFERENCES}

1. Pastor, I. M.; Yus, M. Curr. Org. Chem. 2007, 11, 925.

2. Yadav, J. S.; Reddy, B. V. S.; Krishna, V. H.; Swamy, T.; Kumar, G. Can. J. Chem. 2007, 85, 412.

3. Silva, L. F., Jr.; Quintiliano, S. A. Tetrahedron Lett. 2009, 50, 2256. 